Article

\title{
Structural and Thermal Properties of Ethylene-Norbornene Copolymers Obtained Using Vanadium Homogeneous and SIL Catalysts
}

\author{
Paweł Groch *(D), Anna Bihun-Kisiel, Aleksandra Piontek and Wioletta Ochędzan-Siodłak (D) \\ Faculty of Chemistry, Opole University, Oleska 48, 45-052 Opole, Poland; abihun@uni.opole.pl (A.B.-K.); \\ aolszowy@uni.opole.pl (A.P.); wsiodlak@uni.opole.pl (W.O.-S.) \\ * Correspondence: pawel.groch@uni.opole.pl
}

Received: 22 September 2020; Accepted: 20 October 2020; Published: 22 October 2020

\begin{abstract}
The series of ethylene-norbornene (E-NB) copolymers was obtained using different vanadium homogeneous and supported ionic liquid (SIL) catalyst systems. The ${ }^{13} \mathrm{C}$ and ${ }^{1} \mathrm{H}$ NMR (carbon and proton nuclear magnetic resonance spectroscopy) together with differential scanning calorimetry (DSC) were applied to determine the composition of copolymers such as comonomer incorporation $\left(C_{N B}\right)$, monomer dispersity $(M D)$, monomer reactivity ratio $\left(r_{e}\right)$, sequence length of ethylene $\left(l_{e}\right)$ and tetrad microblock distributions. The relation between the type of catalyst, reaction conditions and on the other hand, the copolymer microstructure, chain termination reaction analyzed by the type of unsaturation are discussed. In addition, the thermal properties of E-NB copolymers such as the melting and crystallization behavior, like also the heterogeneity of composition described by successive the self-nucleation and annealing (SSA) and the dispersity index (DI) were determined.
\end{abstract}

Keywords: ethylene; norbornene; copolymerization; post-metallocene catalyst; NMR investigation; DSC and SSA investigation

\section{Introduction}

Cyclic olefins copolymers (COCs) have gained attention owing to their unique properties, which make them attractive as high-tech engineering plastics. The most versatile and interesting COCs are those of ethylene (E) with norbornene (NB) [1,2]. The COCs produced by copolymerization of ethylene with norbornene are one of few examples of copolymers industrially produced using metallocene catalysts with trade names TOPAS (by TOPAS Advanced Polymers GmbH) [3,4] and APEL (by Mitsui Chemicals, Inc.) [5]. Poly(ethylene-co-norbornene) materials show many interesting properties like a moisture barrier (4-5 times higher than low density polyethylene (LDPE)) [3], good solvent resistance, facile processability, high thermal stability, transparency and stiffness [6]. These copolymers are a promising class of thermoplastics, ranging from highly crystalline solids to elastomers, whose properties depend on the norbornene content and copolymer microstructure [7-10].

The main characteristics of these materials are directly linked to cyclic comonomer content, sequence distribution (isolated ENE units, alternating NEN units or presence of NN dyads and NNN triads), as well as a stereochemical arrangement of norbornene units. It is important to determine the microstructure of copolymers in order to understand their different polymer properties, so that to improve significantly their commercial use [6,11].

Nuclear magnetic resonance (NMR) spectroscopy is an extremely useful tool for understanding the structure of polymer. Especially the ${ }^{13} \mathrm{C}$ NMR is necessary to describe polymer microstructures. In recent years, due to significant development in NMR instrumentation, progress made in calculation methods and in Quantum Mechanical theory has been observed. This helps more accurate prediction 
of NMR resonance frequencies and thus characterization of the microstructure of polymers. One of the methods of description of the E-NB copolymers microstructure is employing a computer optimization routine, which allows the best fit of the microstructural analysis by ${ }^{13} \mathrm{C} N \mathrm{NR}$ spectra and the derivation of reactivity ratios for both first and second-order Markov models. It should be emphasized that the spectra of cyclic olefins are relatively complex due to the presence of stereogenic carbon atoms in the polymer chain per monomer unit. Furthermore, chemical shifts of these copolymers do not obey simple additive rules $[1,12,13]$.

Copolymer microstructure and properties are tightly connected with conditions of reaction and type of catalyst. Nowadays, interest in vanadium complexes is currently growing because they enable to obtain polymers of high molecular weight $\left(M_{w}\right)$ and narrow molecular weight distribution $\left(M_{w} / M_{n}\right)$, copolymers of ethylene with higher 1-olefins or cyclic olefins with high comonomer incorporation in the copolymer chain [1,14-22]. However, a big disadvantage of vanadium compounds is their instability, they are easily reduced to lower, inactive oxidation state. To prevent this, ethyl trichloroacetate (ETA) reactivator is often used. Another method of stabilizing the vanadium active center is applying ligands with electron-donating atoms, oxygen or nitrogen [14,23-35]. In our previous works it was found that the vanadium metallocene and post-metallocene catalysts with oxazoline ligand activated by the traditional organoaluminium compound $\left(\mathrm{AlEt}_{2} \mathrm{Cl}\right)$ and ETA can be successfully used for COC synthesis [35-41].

In order to increase the stability of catalysts in industry, metal complexes are immobilized on a solid support. Simultaneously, it allows controlling polymer microstructure and morphology as well as eliminating reactor fouling. An extremely interesting way to make heterogeneous catalyst is to use so-called supported ionic liquid (SIL) systems. In the SIL system a thin layer of ionic liquid with dissolved catalyst is anchored on a solid, porous, inorganic or organic support [21,42-45]. The SIL systems combine the advantages of homogeneous and heterogeneous catalysis, while reducing their disadvantages [42,43]. Moreover, our group showed that the SIL systems were active both in ethylene polymerization and copolymerization of ethylene with $\alpha$-olefins and cyclic olefins $[21,44,46]$.

This work presents structural and physicochemical analysis of ethylene-norbornene copolymers obtained using homogeneous or heterogeneous (SIL) vanadium metallocene and post-metallocene catalysts. The microstructures of these copolymers were characterized in detail by ${ }^{13} \mathrm{C} N \mathrm{NMR}$ and ${ }^{1} \mathrm{H}$ NMR. The structural properties and compositions of copolymers were analyzed and discussed on the basis of the obtained results with use for example Finneman-Ross and Randall method. It should be noted that in our best knowledge there is no study related to thermal properties of E-NB copolymers due to their usually has an amorphous form. This study was carried out, by means of differential scanning calorimetry (DSC) on obtained polymeric products. In addition, the successive self-nucleation and annealing (SSA) allowed to determine the lamellar thickness, dispersity index and fraction share of obtained E-NB copolymers which are significantly important parameters of semi-crystalline polymeric products.

\section{Materials and Methods}

\subsection{Compounds}

The E-NB copolymers were prepared according to the procedures previously published [21,26,44-46]. The vanadium complexes with the following ligands were applied for the copolymerization reaction: 2-(4,5-dihydro-1,3-oxazolin-2-yl)phenol (C1), 2-(4-methyl-4,5-dihydro-1,3-oxazolin-2-yl)phenol (C2), 2-(5,6-dihydro-4H-1,3-oxazin-2-yl)phenol (C3), 2-(1,3-oxazolin-2-yl)pyridine (C4), 2,6-bis(1,3-oxazolin2-yl)pyridine (C5) and cyclopentadienyl (C6) (Figure 1). Additionally, the C4, C5 and C6 catalysts were immobilized on the silica covered by 1-[3-(triethoxysilyl)propyl]pyridinium ethylchloroaluminate ionic liquid (Figure 2), which results in supported ionic liquid (SIL) catalyst, respectively SIL/C4, SIL/C5 and SIL/C6. The norbornene incorporation in the copolymer chain $\left(C_{N B}\right)$ fell within the range of $4.3-34.7 \mathrm{~mol} \%$, as determined by the ${ }^{13} \mathrm{C}$ NMR method. Molecular weight $\left(M_{w}\right)$ of E-NB copolymers evaluated on an 
Alliance 135 GPCV 2000 apparatus was in the range of $90-1138 \times 10^{3} \mathrm{~g} / \mathrm{mol}$. Neat polyethylenes obtained under the same conditions were used as reference material.

C1

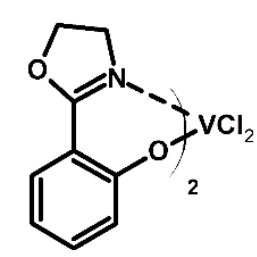

C3<smiles></smiles>

C5

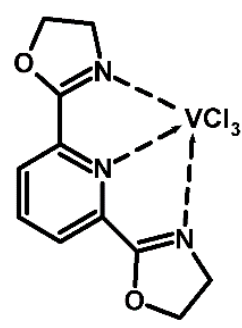

C2<smiles>CC1COC2=C1c1ccccc1OC(Cl)(Cl)C2</smiles>

C4<smiles></smiles>

C6

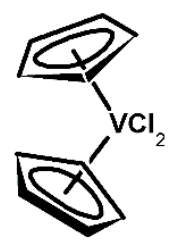

Figure 1. Structures of the vanadium complexes applied for E-NB copolymerization.

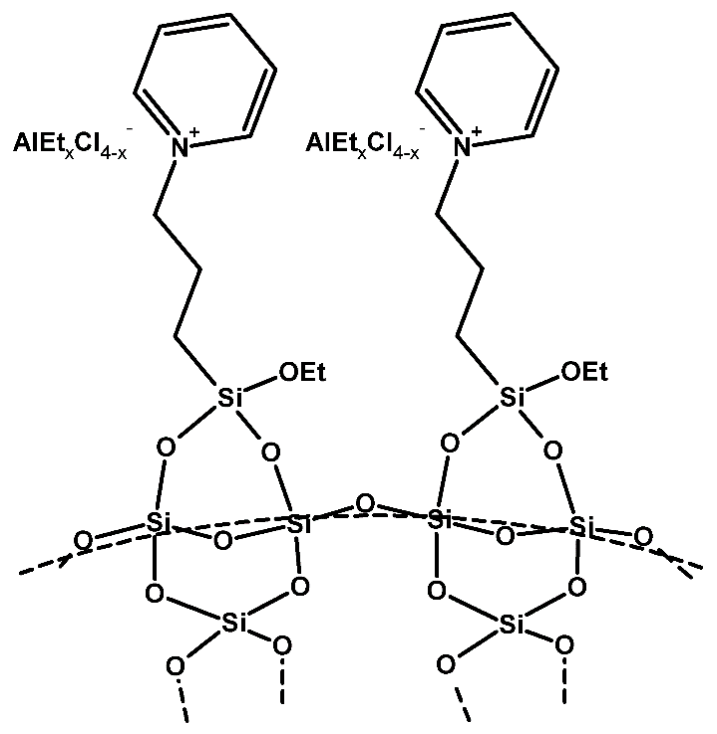

Figure 2. Schematic presentation of silica covered by the ionic liquid.

\subsection{Characterization Techniques}

NMR experiments were performed in standard $5 \mathrm{~mm}$ NMR tubes at $120{ }^{\circ} \mathrm{C}$ in 1,2-dichlorobenzene-d4 using a UltraShield Bruker spectrometer (400 MHz) equipped with a smart probe. ${ }^{1} \mathrm{H}$ NMR spectra were referenced to the residual protons of the non-deuterated solvent used. ${ }^{13} \mathrm{C}$ NMR spectra were referenced internally to the ${ }^{13} \mathrm{C}$ resonances of the NMR solvent. The norbornene 
content in copolymers was calculated according to the formula $[2 I(\mathbf{C} 7)+I(\mathbf{C} 1-\mathbf{C} 2)+I(\mathbf{C} 2-\mathbf{C} 3)] \times$ $100 / 3 I\left(\mathrm{CH}_{2}\right)$, where $I\left(\mathrm{CH}_{2}\right), I(\mathbf{C} 7), I(\mathbf{C} 1-\mathbf{C} 2)$ and $I(\mathbf{C} 2-\mathbf{C} 3)$ are the peak areas in the ranges $26-30,30-36$, 34-42 and 43-54 ppm of ${ }^{13} \mathrm{C}$ NMR spectra [6,47].

Differential scanning calorimetry (DSC) scans were carried out on a DSC1 Mettler Toledo instrument. The sample in an amount of $5 \mathrm{mg}$ was placed in an aluminum pan and the measurement was carried out using a heating and cooling rate of $10{ }^{\circ} \mathrm{C} \mathrm{min}^{-1}$ at nitrogen atmosphere with the gas flow $30 \mathrm{~mL} \mathrm{~min}^{-1}$. In order to remove the thermal history of samples the melting temperature $\left(T_{\mathrm{m}}\right)$ and heat of melting $\left(\Delta H_{\mathrm{m}}\right)$ values were recorded during the second heating. The successive self-nucleation and annealing (SSA) investigation was performed by DSC following the procedure previously published [48] at nitrogen atmosphere with the gas flow of $30 \mathrm{~mL} \mathrm{~min}^{-1}$. The samples were heated up to $170^{\circ} \mathrm{C}$ and maintained at this level for $20 \mathrm{~min}$ and then they were cooled down to $0{ }^{\circ} \mathrm{C}$ at the rate of $5^{\circ} \mathrm{C} \mathrm{min}^{-1}$. This cycling procedure was repeated several times for temperatures from 140 to $67^{\circ} \mathrm{C}$ at $3^{\circ} \mathrm{C}$ intervals [48]. The lamellar thickness for polymeric samples was determined by deconvolution of broad signal in DSC curve and the Gibbs-Thomson Equation (1) [49]:

$$
T_{m}=T_{m}^{o}\left(\frac{1-2 \sigma_{e}}{\Delta H_{f} \times L_{G T}}\right)
$$

The following parametric values were used in calculations [19-21]: $T_{m}^{o}$ equilibrium melting temperature of a perfect crystal is $145.5^{\circ} \mathrm{C}, \Delta H_{f}$ is related to heat of fusion per unit volume for a perfect crystal is $290 \mathrm{~J} \mathrm{~cm}^{-3}$ and $\sigma_{\mathrm{e}}$ is crystallite specific surface free energy fell within the range $90 \mathrm{~mJ} \mathrm{~m}^{-2}$. In addition, the $D I$ values were calculated by the ratio of the melting enthalpy of each peak to the maximum melting enthalpy in the SSA curves of the copolymer sample.

\section{Results}

\subsection{Copolymers Composition}

Table 1 presents the selected parameters of the copolymerization reaction, including the type of catalyst, as well as the selected parameters of the obtained copolymers. The increase of norbornene concentration in the reaction feed results, as expected, in an increase of norbornene content $\left(C_{N B}\right)$ incorporated into polymer chain, irrespective of the kind of catalyst complex used. It should be noted that despite the relatively low range of NB concentration studied, from 0.1 to $1.5 \mathrm{~mol} / \mathrm{dm}^{3}$, the determined $C_{N B}$ values range from 4 up to $35 \mathrm{~mol} \%$. At the highest studied NB concentration in the feed $\left(1.5 \mathrm{~mol} / \mathrm{dm}^{3}\right)$, the $C_{N B}$ values vary in the range $27-35 \mathrm{~mol} \%$. Some correlation between the catalyst structure and the $C_{N B}$ values can be observed. In the series of the catalysts with phenolate ligands the norbornene incorporation is higher for $\mathbf{C} 2$ and $\mathbf{C} 3$ than for $\mathbf{C} 1$ analogue. Similarly, the norbornene incorporation is higher for the catalyst with bidentate $\mathbf{C} 4$ than tridentate $\mathbf{C} 5$ pyridinium ligands. It should be noticed higher $C_{N B}$ values for $\mathbf{C} 4$ as compared to $\mathbf{C} 1$ catalyst with the same oxazoline substituent. High NB incorporation was also obtained using vanadocene catalyst (C6). In case of the SIL supported catalyst systems the presented results indicate that they produce the copolymer with higher NB content in comparison with homogeneous analogues, regardless of the type of catalyst.

The copolymers are characterized by molecular weight $\left(M_{w}\right)$ in the range from $90 \times 10^{3}$ to $1100 \times 10^{3} \mathrm{~g} / \mathrm{mol}$, which decrease with increasing content of NB, like also by high homogeneity $\left(M_{w} / M_{n}\right.$ about 2). The copolymers produced using the SIL catalysts show generally higher molecular weights (especially at the extreme content in the reaction feed) in comparison to the copolymers obtained over non-supported analogues (Table 1). 
Table 1. Selected parameters of E-NB copolymers and copolymerization reaction performed using studied vanadium catalysts.

\begin{tabular}{|c|c|c|c|c|c|c|c|c|}
\hline Item & Catalyst & $\begin{array}{l}\text { NB Feed } \\
{\left[\mathrm{mol} / \mathrm{dm}^{3}\right]}\end{array}$ & $\begin{array}{c}C_{N B} \\
{[\mathrm{~mol} \%]}\end{array}$ & $\begin{array}{c}M_{w} \times 10^{-3} \\
{[\mathrm{~g} / \mathrm{mol}]}\end{array}$ & $M_{w} / M_{n}$ & $r_{e}$ & $l_{e}$ & $M D$ \\
\hline 1 & \multirow{3}{*}{$\mathrm{C} 1$} & 0.5 & 12.3 & 260 & 1.6 & \multirow{3}{*}{8.6} & 8.1 & 87.7 \\
\hline 2 & & 1.0 & 22.1 & 200 & 1.8 & & 4.5 & 77.9 \\
\hline 3 & & 1.5 & 27.5 & 180 & 1.9 & & 3.6 & 72.5 \\
\hline 4 & \multirow{3}{*}{$\mathrm{C} 2$} & 0.5 & 17.1 & 160 & 1.7 & \multirow{3}{*}{12.2} & 5.8 & 82.9 \\
\hline 5 & & 1.0 & 20.7 & 130 & 1.9 & & 4.8 & 79.3 \\
\hline 6 & & 1.5 & 27.2 & 90 & 2.2 & & 3.7 & 72.8 \\
\hline 7 & \multirow{3}{*}{$\mathrm{C} 3$} & 0.5 & 19.4 & 190 & 1.7 & \multirow{3}{*}{10.8} & 5.2 & 80.6 \\
\hline 8 & & 1.0 & 26.5 & 170 & 1.7 & & 3.8 & 73.5 \\
\hline 9 & & 1.5 & 30.1 & 160 & 1.9 & & 3.3 & 69.9 \\
\hline 10 & \multirow{3}{*}{$\mathrm{C} 4$} & 0.5 & 15.5 & 679 & 1.9 & \multirow{3}{*}{7.2} & 6.5 & 84.5 \\
\hline 11 & & 1.0 & 23.0 & 420 & 1.9 & & 4.3 & 77.0 \\
\hline 12 & & 1.5 & 31.8 & 187 & 2.0 & & 3.1 & 68.2 \\
\hline 13 & \multirow{3}{*}{ SIL/C4 } & 0.5 & 18.5 & 852 & 2.0 & \multirow{3}{*}{8.7} & 5.4 & 81.5 \\
\hline 14 & & 1.0 & 25.2 & 461 & 2.3 & & 4.0 & 74.8 \\
\hline 15 & & 1.5 & 31.6 & 214 & 2.5 & & 3.2 & 68.4 \\
\hline 16 & \multirow{3}{*}{ C5 } & 0.5 & 14.4 & 679 & 1.9 & \multirow{3}{*}{7.9} & 6.9 & 85.6 \\
\hline 17 & & 1.0 & 21.9 & 420 & 1.9 & & 4.6 & 78.1 \\
\hline 18 & & 1.5 & 30.0 & 178 & 2.0 & & 3.3 & 69.6 \\
\hline 19 & \multirow{3}{*}{ SIL/C5 } & 0.5 & 18.9 & 679 & 1.9 & \multirow{3}{*}{6.9} & 5.3 & 81.1 \\
\hline 20 & & 1.0 & 26.8 & 420 & 1.9 & & 3.7 & 73.2 \\
\hline 21 & & 1.5 & 34.7 & 198 & 2.0 & & 2.9 & 65.3 \\
\hline 22 & \multirow{3}{*}{ C6 } & 0.1 & 4.3 & 1047 & 2.5 & \multirow{3}{*}{6.5} & 23.3 & 95.7 \\
\hline 23 & & 1.0 & 23.6 & 470 & 2.9 & & 4.2 & 76.4 \\
\hline 24 & & 1.5 & 32.9 & 157 & 2.0 & & 3.0 & 67.1 \\
\hline 25 & \multirow{3}{*}{ SIL/C6 } & 0.1 & 5.7 & 1138 & 1.5 & \multirow{3}{*}{6.0} & 17.5 & 94.3 \\
\hline 26 & & 1.0 & 26.1 & 265 & 2.9 & & 3.8 & 73.9 \\
\hline 27 & & 1.5 & 35.3 & 225 & 3.0 & & 2.8 & 64.7 \\
\hline
\end{tabular}

$C_{N B}$-determined by ${ }^{13} \mathrm{C} \mathrm{NMR}, M_{w}$ and $M_{w} / M_{n}$ obtained by GPC, $l_{e}$-number-average sequence length of ethylene, $r_{e}$-reactivity ratio, $M D-$ monomer dispersity.

The influence of structure of complexes on incorporation ability as well as the difference between the non-supported and SIL catalyst systems is shown by the reactivity ratios of ethylene $\left(r_{e}\right)$ calculated using the Fineman-Ross method [50] (Table S1 in the supplementary file and Table 1). The Fineman-Ross method was successfully used in the work related to the copolymerization of ethylene with norbornene [51].

In case of the E-NB copolymerization over homogeneous catalytic complexes, the $r_{e}$ values increase as follows: C6 (6.5) > C4 (7.2) > C5 (7.9) > C1 (8.6) > C3 (10.8) > C2 (12.2) (Table 1, items 1-12, 16-18, 22-24). It should be noted that the presence of methyl substituent in oxazoline ligands in C2 complex results in increase of $r_{e}$ value (decrease of norbornene reactivity) in comparison with C1 complex. This result is associated with an increase in electron density in ligand and hence stronger interaction of ligand with metal center what affects increase of steric hindrance. In turn, a slightly larger oxazine substituents in $\mathbf{C} 3$ leads to higher steric hindrance in comparison with oxazoline substituents in $\mathbf{C} \mathbf{1}$ and increase of the value $r_{e}$. Interestingly, despite the fact that the $\mathbf{C} 4$ pyridinium complex is characterized by less steric hindrance than $\mathbf{C} \mathbf{1}$ complex, the value of $r_{e}$ is markedly lower. In addition, the tridentate C5 pyridine complex with larger ligand which surrounded the metal center, exhibits only slightly higher $r_{e}$ value in comparison with bidentate $\mathbf{C} 4$ pyridine complex.

The comparison of the catalysts systems C4, SIL/C4, C5 and SIL/C5, C6 and SIL/C6 (Table 1, items 10-15, 16-21 and 22-27) shows lower values of $r_{e}$ for the SIL-supported catalysts than 
non-supported analogues. The highest influence of immobilization process on the reactivity of norbornene is observed in the catalyst SIL/C4 (Table 1, items 10-15). This shows that the immobilization of complexes on support generally causes an increase of reactivity ratio of norbornene.

In order to determine the differences between the microstructure of the analyzed copolymers, the structural parameters characterizing the copolymer chain were calculated using the Randall method [52]. As expected, the number-average sequence length of ethylene $\left(l_{e}\right)$ decreases with the increase of NB concentration in the feed, which shows that shorter ethylene sequences are created. Regardless of the type of catalyst, there is clear correlation between norbornene content $\left(C_{N B}\right)$ in the copolymer and the value of $l_{e}$, which decreases with the increasing ability of the catalytic system to incorporate norbornene in the polymer chain. Again, the SIL supported catalyst reveal lower values of $l_{e}$, which indicates shorter length of ethylene sequences as compared to non-supported analogues.

The calculated values of monomer dispersity $(M D)$ for the E-NB copolymers also depends on the norbornene concentration and incorporation. For low NB incorporation the $M D$ values are in the range of 96-80, which indicates that all or almost all norbornene units in the macromolecules are isolated (Table 1, items, 1, 4, 7, 10, 13, 16, 19, 22 and 25, Figures S1-S27 in the supplementary file). Decrease of $M D$ values indicates higher NB incorporation and the presence of different kind of norbornene sequence.

The type of sequences was evaluated by the E-NB copolymer tetrad distributions using ${ }^{13} \mathrm{C} N \mathrm{NR}$ method (Figure 3).

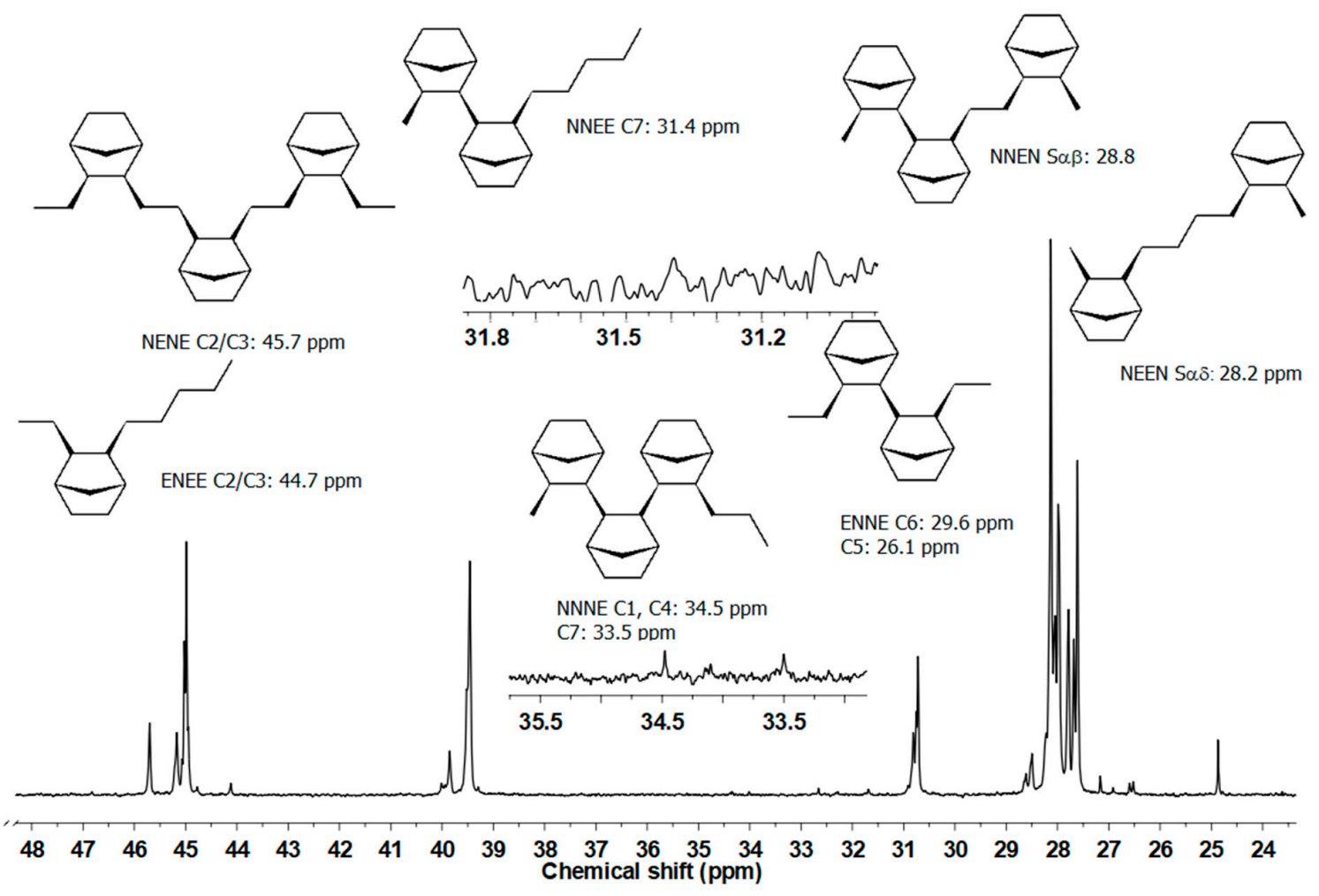

Figure $3 .{ }^{13} \mathrm{C}$ nuclear magnetic resonance (NMR) spectra of E-NB copolymer synthesized by SIL/C5 catalytic system.

The results were obtained only for copolymers with the lowest $M D$ values (from 64.7 to 72.8 ) synthesized over homogeneous and SIL catalyst systems (Table 2). It should be noted that in all the studied copolymers the NNNN tetrads were not observed. The NNNE tetrads did not appear or appear in small amount in the copolymers obtained using homogenous catalyst (C2-C4), despite to very high norbornene content. Immobilization of complexes on support generally results in much higher content of NENE, NNEE, ENNE as well as NNNE tetrads (alternating E/N units and norbornene 
blocks, respectively). Moreover, immobilization process causes decrease of isolated ENEE tetrads (Table 2, items 1-21 and 24, 27).

Table 2. Tetrad distributions of E-NB copolymers obtained over different homogeneous and SIL catalyst systems.

\begin{tabular}{|c|c|c|c|c|c|c|c|c|c|c|c|c|}
\hline \multirow{2}{*}{${ }^{\mathrm{a}}$ Item } & \multirow{2}{*}{ Catalyst } & \multirow{2}{*}{$\begin{array}{l}{ }^{\mathrm{b}} C_{N B} \\
{[\mathrm{~mol} \%]}\end{array}$} & \multicolumn{10}{|c|}{ b Tetrad } \\
\hline & & & EEEE & NEEE & NEEN & ENEE & NNEE & NENE & NNEN & ENNE & NNNE & NNNN \\
\hline 1 & $\mathrm{C} 1$ & 27.5 & 0.651 & 0.068 & 0.045 & 0.110 & 0.004 & 0.107 & 0.005 & 0.007 & 0.005 & 0.000 \\
\hline 6 & $\mathrm{C} 2$ & 27.2 & 0.738 & 0.049 & 0.029 & 0.104 & 0.000 & 0.064 & 0.015 & 0.001 & 0.000 & 0.000 \\
\hline 9 & C3 & 30.1 & 0.587 & 0.073 & 0.062 & 0.117 & 0.000 & 0.126 & 0.035 & 0.000 & 0.000 & 0.000 \\
\hline 12 & C4 & 31.8 & 0.651 & 0.072 & 0.059 & 0.109 & 0.003 & 0.104 & 0.000 & 0.002 & 0.000 & 0.000 \\
\hline 15 & SIL/C4 & 31.6 & 0.613 & 0.074 & 0.056 & 0.093 & 0.006 & 0.130 & 0.004 & 0.012 & 0.012 & 0.000 \\
\hline 18 & C5 & 30.0 & 0.669 & 0.078 & 0.062 & 0.031 & 0.007 & 0.125 & 0.011 & 0.008 & 0.009 & 0.000 \\
\hline 21 & SIL/C5 & 34.7 & 0.680 & 0.084 & 0.058 & 0.014 & 0.003 & 0.133 & 0.005 & 0.003 & 0.020 & 0.000 \\
\hline 24 & C6 & 32.9 & 0.666 & 0.067 & 0.040 & 0.112 & 0.002 & 0.107 & 0.000 & 0.002 & 0.004 & 0.000 \\
\hline 27 & SIL/C6 & 35.3 & 0.620 & 0.071 & 0.055 & 0.110 & 0.007 & 0.120 & 0.000 & 0.009 & 0.008 & 0.000 \\
\hline
\end{tabular}

\subsection{Unsaturation Group Study of E-NB Copolymers}

The catalytic systems have an influence on the chain termination reaction in the E-NB copolymerization as it is shown by determination of the type of unsaturated groups for the products obtained using the ${ }^{1} \mathrm{H}$ NMR (Figure 4).

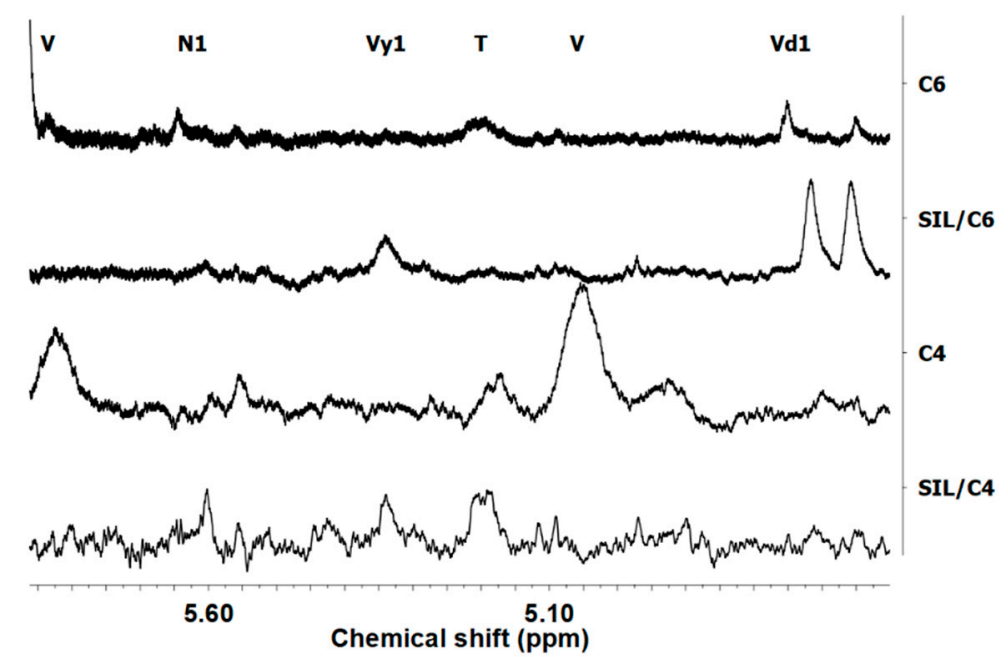

Figure 4. ${ }^{1} \mathrm{H}$ NMR spectra of E-NB copolymers obtained using homogeneous (C6, C4) and heterogeneous (SIL/C6, SIL/C4) catalyst with the highest NB incorporation degree (Table 1, item 27, 24, $12,15)$.

The ${ }^{1} \mathrm{H}$ NMR study was performed for the E-NB copolymers obtained by the selected homogeneous and heterogeneous catalyst (C4, SIL/C4), in which a considerable influence of immobilization on the value of $r_{e}$ was observed, as well as the metallocene (C6, SIL/C6), for comparison of both types of complexes. The spectra of E-NB copolymers show the presence of a large number of peaks related to different kind of unsaturation groups, which indicates different way of termination reactions in copolymerization.

All resonances presented in the ${ }^{1} \mathrm{H}$ NMR spectra were assigned by comparison with the literature data [53]. The multiples within the range of 5.9-5.7 and 5.0-4.9 ppm are assigned to vinyl groups $\left(\mathrm{CH}_{2}=\mathrm{CHR} ; \mathrm{V}\right)$, which appears due to $\beta$-H elimination after ethylene insertion. The signal at $5.6 \mathrm{ppm}$ is characteristic for norbornenyl end group structure. The signal at $5.3 \mathrm{ppm}$ is assigned to the vinylene 
unsaturated groups after 2,1-insertion $\left(\mathrm{RCH}=\mathrm{CHR}^{\prime} ; \mathrm{Vy} 1\right)$. It should be noted that the signal at $5.2 \mathrm{ppm}$ is also observed, which corresponds to the presence of trisubstituted vinylene groups ( $R R^{\prime} C=C H R^{\prime \prime}$; $\mathrm{T})$. This kind of unsaturation is formed when the comonomer is inserted as the last monomer and this is followed by isomerization and $\beta-\mathrm{H}$ transfer to the metal center [53]. In addition, two peaks at $4.73 \mathrm{ppm}$ and $4.60 \mathrm{ppm}$ correspond to the geminal protons of two different vinylidene structures (VD1 and VD2, internal and external unsaturated groups, respectively).

It should be noted that in case of $\mathbf{C} 6$ and $\mathbf{C 6 / S I L}$ metallocene complexes the termination reaction occurs in an unusual way. The metallocene $\mathbf{C 6}$ and SIL/C6 do not prefer the termination reaction, followed by the $\beta-\mathrm{H}$ elimination after the ethylene insertion, which is shown by the absence of vinyl groups $\left(\mathrm{CH}_{2}=\mathrm{CHR} ; \mathrm{V}\right)$ in the range of 5.9-5.7 and 5.0-4.9 ppm (Figure 4). These results are unusual for the polymerization preformed using the metallocene catalytic systems, in which the $\beta-\mathrm{H}$ elimination is dominant termination reaction [54]. This phenomenon can be explained by the influence of alkylaluminium activator on termination reaction, what was previously observed in our work [55]. The dominant unsaturated groups in the E-NB copolymerization catalyzed by the homogeneous C6 complex were trisubstituted vinylene like also vinylidene groups (T, VD1 and VD2). However, the immobilization of metallocene complex results in disappearance of the trisubstituted vinylene groups in the copolymer and appearance of vinylene groups. These results clearly indicate that the ionic liquid influences both the suppression of isomerization reaction and the $\beta-\mathrm{H}$ transfer to the metal center of the last monomer and favors the comonomer 2,1-type insertion. It should be noted that the ionic liquid significant changes of the catalytic mechanism of termination polymer chain of metallocene complex.

The E-NB copolymers obtained by the homogeneous catalyst $\mathrm{C} 4$ are characterized by the presence of trisubstituted vinylene groups in contrast to metallocene $\mathbf{C 6}$ and SIL/C6 complexes. This result indicates that the alkylaluminium activator does not influence on mechanism of termination reaction in copolymerization. In turn, the immobilization of postmetallocene complex leads to suppression of $\beta-\mathrm{H}$ elimination reaction, which is associated with the change of pathway of termination reaction excluding influence of activator (Figure 4). In addition, the observed presence of the vinylene groups in copolymers indicates that the ionic liquid causes the 2,1-type of insertion of comonomer.

\subsection{Thermal Properties of Copolymers}

The kind of catalytic system and degree of norbornene incorporation influence on the melting and crystallization behavior of the E-NB copolymers as it is shown using DSC method (Figure 5 and Figures S28-S32 in the Supplementary File).

The E-NB copolymers obtained over the homogeneous catalytic systems with the highest comonomer degree were amorphous (Figure 5a,c and Figures S28-S31 in the Supplementary File). The similar results are observed in case of ethylene copolymerization with norbornene over homogeneous metallocene catalytic systems [6]. Noteworthy is that the E-NB copolymers synthesized using the immobilized catalytic systems (SIL/C4, SIL/C5 and SIL/C6) are characterized by generally increased intensity of melting peak, what is atypical behavior of the E-NB copolymers (Figure $5 b, d$ and Figure S32 in the Supplementary File). This phenomenon can be explained by packing of the growing polymer chain in the nonpolar part of ionic liquid in catalytic system, which in turn leads to markedly increased crystalline structure.

For the copolymers synthesized over the catalysts SIL/C4, SIL/C5 and SIL/C6, the endothermic peak in the DSC thermograms became broader with the increase of NB content (Figure $5 b, d$ and Figure S32 in the Supplementary File), what suggests the increase copolymers heterogeneity.

The NB incorporated into polymer chain causes not only the increase of crystalline structure but also increase of the heterogeneity of composition of copolymer chain in comparison with neat PE.

Therefore, the successive self-nucleation and annealing (SSA) analyses were performed by DSC, which is a commonly used thermal fractionation technique $[48,56]$. The SSA were performed for the selected copolymers synthesized over homogeneous catalyst C4, C6 and immobilized counterparts 
SIL/C4, SIL/C6 at the highest NB content (Table 1, items 12, 24 and 15, 27). The multiple melting peaks were observed in DSC curves for all of the analyzed copolymer samples but some differences in the number of peaks as well as in position of their maxima and in intensity were observed (Figure 6).

a)

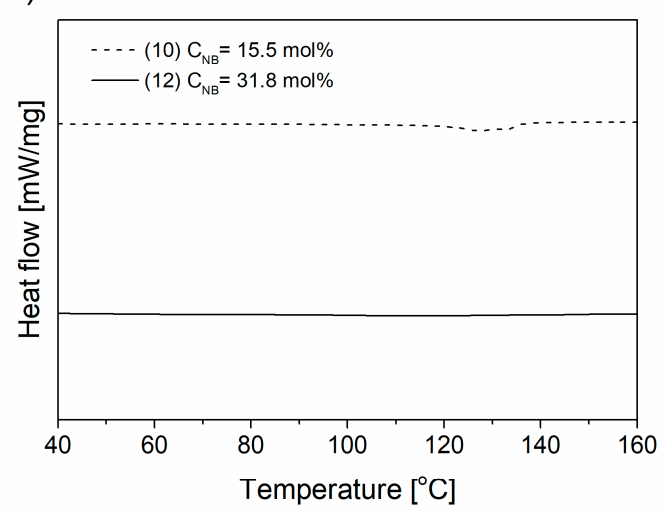

c)

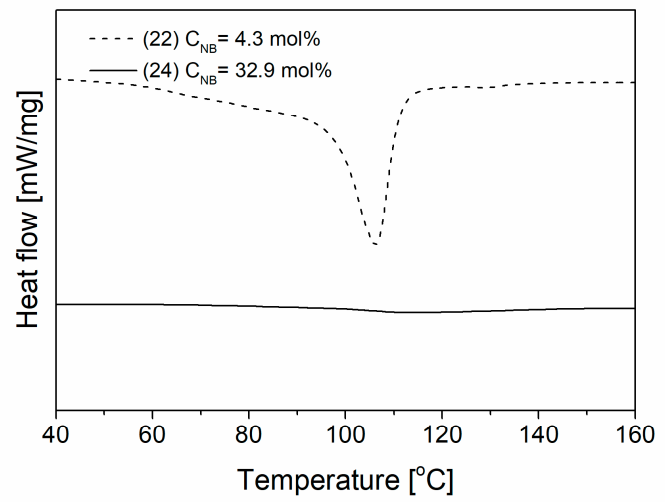

b)

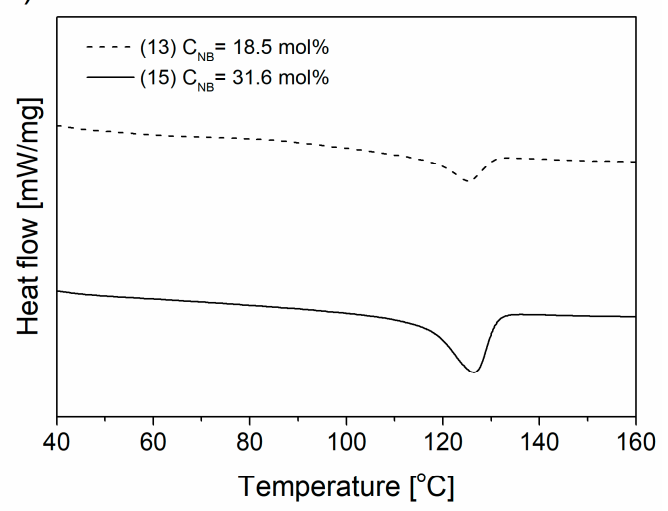

d)

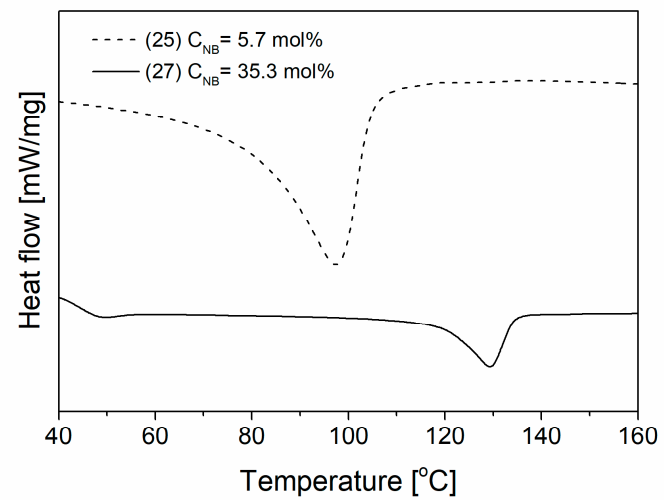

Figure 5. The endothermic curves of E-NB copolymers obtained by C4 (a), SIL/C4 (b), C6 (c), SIL/C6 (d) complex (items according to Table 1).

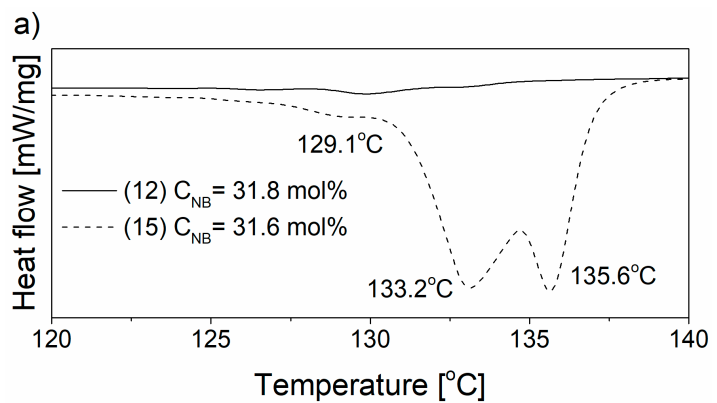

b)

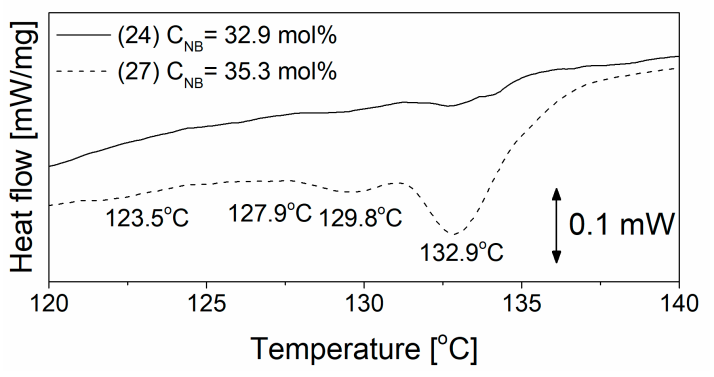

Figure 6. Successive self-nucleation and annealing (SSA) curves of E-NB copolymers obtained by catalysts (a) C4, SIL/C4 and (b) C6, SIL/C6 (items according to Table 1). 
The E-NB copolymer synthesized by the catalyst SIL/C4 with $31.6 \mathrm{wt} \%$ of NB is characterized by three melting peaks at $129.1,133.2$ and $135.6^{\circ} \mathrm{C}$. It is interesting to note that the melting peak at $135.6^{\circ} \mathrm{C}$ is very similar to that of neat polyethylene and this at $136.3^{\circ} \mathrm{C}$ can be associated with the presence of polyethylene sequence in the copolymer chain with a significantly low NB content. In turn, for the copolymer produced by the catalyst SIL/C6, four separated peaks, at 123.5, 127.9, 129.8 and $132.9^{\circ} \mathrm{C}$, are observed in the thermogram. The number of peaks shows that the composition of this copolymer is much more heterogeneous, in contrast to that obtained using the catalyst SIL/C4 (Figure 6). The fraction with the lowest lamellar thicknesses can be assigned to the presence of NNNE tetrads, which is confirmed by ${ }^{13} \mathrm{C}$ NMR (Table 2). In addition, the dispersity index (DI) was determined in order to evaluate the heterogeneity of E-NB copolymers (Table 3).

Table 3. DI values for E-NB copolymers obtained over SIL catalysts.

\begin{tabular}{|c|c|c|c|c|c|c|}
\hline \multirow{2}{*}{ Item } & \multirow{2}{*}{ Catalyst } & \multirow{2}{*}{${ }^{\text {a }} C_{N B}[\mathrm{~mol} \%]$} & \multicolumn{4}{|c|}{$D I$} \\
\hline & & & F1 & F2 & F3 & F4 \\
\hline 15 & SIL/C4 & 31.6 & 0.52 & 1.00 & 0.13 & - \\
\hline 27 & SIL/C6 & 35.3 & 0.17 & 0.30 & 0.24 & 1.00 \\
\hline
\end{tabular}

The $D I$ values indicates that the E-NB copolymer synthesized using the catalyst SIL/C4 is more homogeneous in comparison with polymer obtained using the metallocene analogue SIL/C6, despite the similar NB content. It should be explained that the E-NB copolymer produced using the catalyst SIL/C4 is characterized by a constant separation of ethylene sequence in copolymer chain, what causes an appearance of endothermic DSC peaks due to segregation of a constant crystallisable sequence length. Longer segments recrystallized in longer lamellar crystals melt at higher temperatures. The relative number of lamellas having different thicknesses were determined based on the values of $\Delta H_{m}$ for each peak in the SSA thermograms (Figure 7). The catalyst SIL/C4 produces the E-NB copolymer with higher lamella thickness in comparison with the metallocene analogue SIL/C6.

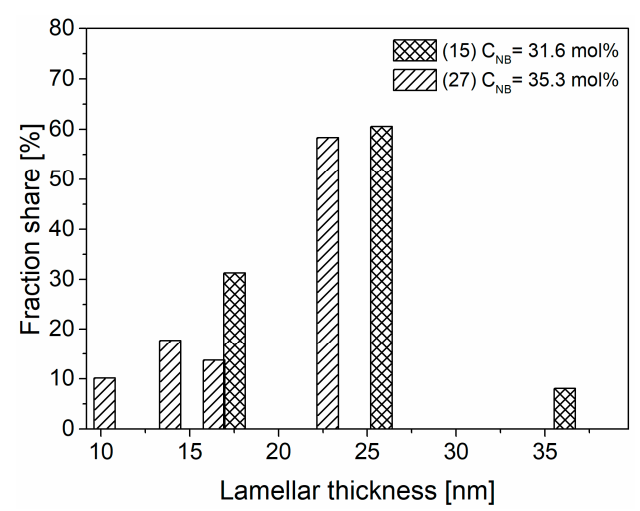

Figure 7. Distribution of lamellar thickness for E-NB copolymers obtained using the catalysts SIL/C4 and SIL/C6 (items according to Table 1).

\section{Conclusions}

The presented study indicates that the microstructure and thermal properties of the ethylene-norbornene copolymers produced using vanadium catalysts depend on the type of catalyst used. Both the homogeneous catalyst systems (C1-C6) and their heterogeneous silica supported ionic liquid analogues (SIL/C4-C6) were applied. The homogenous catalysts produce the copolymers, which differ in the structure and properties. This seem to be associated with formation sterically more open active pocket of the catalyst center for coordination of the bulky NB comonomer, connected with ligand distortion (C1-C3) or denticity (C4, C5), which is further evidenced by high NB incorporation obtained 
using vanadocene catalyst (C6). However, these differences are moderate, in particular, at higher initial NB concentration in the feed. The differences between the homogeneous and supported ionic liquid (SIL) catalysts can be seen, which can be explained by specific interaction of the ionic liquid with the catalyst system. The ionic liquid environment associates the ionic catalyst center, in particular, its anionic counterpart. These results in the formation of weaker ion pair, which enables better access to active center. The nano-segregated structure of ionic liquids should also be considered. The polar ionic liquid phase imposes more tightly packing of the growing non-polar copolymer chain, which results in higher copolymer crystallinity.

The immobilization of catalyst systems generally results in higher reactivity of norbornene in copolymerization with ethylene and in a consequence, in higher norbornene content in the copolymers. In addition, the E-NB copolymers produced using supported catalysts are characterized by higher content of alternating and norbornene blocks and lower content of isolated blocks in comparison with the homogeneous analogues. The chain termination reaction also depends on the kind of catalytic system. The immobilization of complexes significantly influences the way of chain termination reaction in comparison with homogeneous analogue.

The thermal properties of copolymers strongly depend on the kind of catalytic system. The E-NB copolymers obtained by the homogeneous catalytic system have amorphous form in contrast to the products synthesized by the supported SIL catalysts, which are characterized by semi-crystalline structure. The growing polymer chain is located in the limited space of nonpolar part of the ionic liquid, which results in formation of crystalline structure. In addition, the SSA analysis of E-NB copolymers obtained by the supported SIL catalyst with similar NB content reveals that higher homogeneity and lamellar thickness have copolymers produced using the postmetallocene catalyst.

Supplementary Materials: The following are available online at http://www.mdpi.com/2073-4360/12/11/2433/s1, Figure S1: The ${ }^{13} \mathrm{C}$ NMR spectrum of E-NB copolymer with (1) $\mathrm{C}_{\mathrm{NB}}=12.3 \mathrm{~mol} \%$ obtained by $\mathrm{C} 1$ complex (item according to Table 1), Figure S2: The ${ }^{13} \mathrm{C}$ NMR spectrum of E-NB copolymer with (2) $C_{\mathrm{NB}}=22.1 \mathrm{~mol} \%$ obtained by $\mathrm{C} 1$ complex (item according to Table 1), Figure S3: The ${ }^{13} \mathrm{C}$ NMR spectrum of E-NB copolymer with (3) $\mathrm{C}_{\mathrm{NB}}=27.5 \mathrm{~mol} \%$ obtained by $\mathrm{C} 1$ complex (item according to Table 1), Figure S4: The ${ }^{13} \mathrm{C}$ NMR spectrum of E-NB copolymer with (4) $\mathrm{C}_{\mathrm{NB}}=17.1 \mathrm{~mol} \%$ obtained by C2 complex (item according to Table 1), Figure S5: The ${ }^{13} \mathrm{C}$ NMR spectrum of E-NB copolymer with (5) $\mathrm{C}_{\mathrm{NB}}=20.7 \mathrm{~mol} \%$ obtained by $\mathrm{C} 2$ complex (item according to Table 1), Figure S6: The ${ }^{13} \mathrm{C}$ NMR spectrum of E-NB copolymer with (6) $C_{N B}=27.2 \mathrm{~mol} \%$ obtained by C2 complex (item according to Table 1), Figure S7: The ${ }^{13} \mathrm{C}$ NMR spectrum of E-NB copolymer with (7) $C_{N B}=19.4$ mol\% obtained by C3 complex (item according to Table 1), Figure S8: The ${ }^{13} \mathrm{C}$ NMR spectrum of E-NB copolymer with (8) $\mathrm{C}_{\mathrm{NB}}=26.5 \mathrm{~mol} \%$ obtained by $\mathrm{C} 3$ complex (item according to Table 1), Figure S9: The ${ }^{13} \mathrm{C}$ NMR spectrum of E-NB copolymer with (9) $\mathrm{C}_{\mathrm{NB}}=30.1 \mathrm{~mol} \%$ obtained by $\mathrm{C} 3$ complex (item according to Table 1), Figure S10: The ${ }^{13} \mathrm{C}$ NMR spectrum of E-NB copolymer with (10) $\mathrm{C}_{\mathrm{NB}}=15.5 \mathrm{~mol} \%$ obtained by $\mathrm{C} 4$ complex (item according to Table 1), Figure S11: The ${ }^{13} \mathrm{C}$ NMR spectrum of E-NB copolymer with (11) $\mathrm{C}_{\mathrm{NB}}=23.0 \mathrm{~mol} \%$ obtained by C4 complex (item according to Table 1), Figure S12: The ${ }^{13} \mathrm{C}$ NMR spectrum of E-NB copolymer with (12) $C_{N B}=31.8$ mol\% obtained by $\mathbf{C} 4$ complex (item according to Table 1), Figure S13: The ${ }^{13} \mathrm{C}$ NMR spectrum of E-NB copolymer with (13) $\mathrm{C}_{\mathrm{NB}}=18.5 \mathrm{~mol} \%$ obtained by SIL/C4 complex (item according to Table 1), Figure S14: The ${ }^{13} \mathrm{C}$ NMR spectrum of E-NB copolymer with (14) $\mathrm{C}_{\mathrm{NB}}=25.2 \mathrm{~mol} \%$ obtained by SIL/C4 complex (item according to Table 1), Figure S15: The ${ }^{13} \mathrm{C}$ NMR spectrum of E-NB copolymer with (15) $\mathrm{C}_{\mathrm{NB}}=31.6 \mathrm{~mol} \%$ obtained by SIL/C4 complex (item according to Table 1), Figure S16: The ${ }^{13} \mathrm{C}$ NMR spectrum of E-NB copolymer with (16) $\mathrm{C}_{\mathrm{NB}}=14.4 \mathrm{~mol} \%$ obtained by C5 complex (item according to Table 1), Figure S17: The ${ }^{13} \mathrm{C}$ NMR spectrum of E-NB copolymer with (17) $\mathrm{C}_{\mathrm{NB}}=21.9 \mathrm{~mol} \%$ obtained by $\mathrm{C} 5$ complex (item according to Table 1), Figure S18: The ${ }^{13} \mathrm{C}$ NMR spectrum of E-NB copolymer with (18) $\mathrm{C}_{\mathrm{NB}}=30.0 \mathrm{~mol} \%$ obtained by $\mathrm{C} 5$ complex (item according to Table 1), Figure S19: The ${ }^{13} \mathrm{C}$ NMR spectrum of E-NB copolymer with (19) $\mathrm{C}_{\mathrm{NB}}=18.9 \mathrm{~mol} \%$ obtained by SIL/C5 complex (item according to Table 1), Figure S20: The ${ }^{13} \mathrm{C}$ NMR spectrum of E-NB copolymer with (20) $C_{\mathrm{NB}}=26.8 \mathrm{~mol} \%$ obtained by SIL/C5 complex (item according to Table 1), Figure S21: The ${ }^{13} \mathrm{C}$ NMR spectrum of E-NB copolymer with (21) $\mathrm{C}_{\mathrm{NB}}=34.7 \mathrm{~mol} \%$ obtained by SIL/C5 complex (item according to Table 1), Figure S22: The ${ }^{13} \mathrm{C}$ NMR spectrum of E-NB copolymer with (29) $C_{\mathrm{NB}}=4.3 \mathrm{~mol} \%$ obtained by $\mathrm{C} 6$ complex (item according to Table 1), Figure S23: The ${ }^{13} \mathrm{C}$ NMR spectrum of E-NB copolymer with (30) $\mathrm{C}_{\mathrm{NB}}=23.6 \mathrm{~mol} \%$ obtained by $\mathrm{C} 6$ complex (item according to Table 1), Figure S24: The ${ }^{13} \mathrm{C}$ NMR spectrum of E-NB copolymer with (31) $C_{\mathrm{NB}}=32.9 \mathrm{~mol} \%$ obtained by $\mathbf{C} 6$ complex (item according to Table 1), Figure S25: The ${ }^{13} \mathrm{C}$ NMR spectrum of E-NB copolymer with (32) $\mathrm{C}_{\mathrm{NB}}=5.7 \mathrm{~mol} \%$ obtained by SIL/C6 complex (item according to Table 1), Figure S26: The ${ }^{13} \mathrm{C}$ NMR 
spectrum of E-NB copolymer with (33) $\mathrm{C}_{\mathrm{NB}}=26.1 \mathrm{~mol} \%$ obtained by SIL/C6 complex (item according to Table 1), Figure S27: The ${ }^{13} \mathrm{C}$ NMR spectrum of E-NB copolymer with (34) $\mathrm{C}_{\mathrm{NB}}=35.3 \mathrm{~mol} \%$ obtained by SIL/C6 complex (item according to Table 1), Figure S28: The endothermic curves of E-NB copolymers obtained by C1 complex (items according to Table 1), Figure S29: The endothermic curves of E-NB copolymers obtained by C2 complex (items according to Table 1), Figure S30: The endothermic curves of E-NB copolymers obtained by C3 complex (items according to Table 1), Figure S31: The endothermic curves of E-NB copolymers obtained by C5 complex (items according to Table 1), Figure S32: The endothermic curves of E-NB copolymers obtained by SIL/C5 complex (items according to Table 1). Table S1. Structural parameters characterizing the ethylene/norbornene copolymers.

Author Contributions: Conceptualization, P.G.; methodology, P.G.; software, P.G.; validation, P.G.; formal analysis, P.G.; investigation, A.B.-K. and A.P.; resources, A.B.-K.; data curation, W.O.-S.; writing-original draft preparation, P.G. and W.O.-S.; writing - review and editing, P.G.; visualization, P.G.; supervision, W.O.-S.; project administration, W.O.-S.; funding acquisition, W.O.-S. All authors have read and agreed to the published version of the manuscript.

Funding: This research received no external funding.

Conflicts of Interest: The authors declare no conflict of interest.

\section{References}

1. Leone, G.; Pierro, I.; Zanchin, G.; Forni, A.; Bertini, F.; Rapallo, A.; Ricci, G. Vanadium(III)-catalyzed copolymerization of ethylene with norbornene: Microstructure at tetrad level and reactivity ratios. J. Mol. Catal. A Chem. 2016, 424, 220-231. [CrossRef]

2. Tritto, I.; Boggioni, L.; Scalcione, G.; Sidari, D.; Galotto, N.G. Novel norbornene copolymers with transition metal catalysts. J. Organomet. Chem. 2015, 798, 367-374. [CrossRef]

3. Add a Layer of COC to Boost Polyolefin Film Properties. Available online: https://www.ptonline.com/ articles/add-a-layer-of-coc-to-boost-polyolefin-film-properties (accessed on 25 October 2011).

4. Advanced Resins for Your Leading Products. Available online: https://topas.com/products/topas-cocpolymers (accessed on 4 May 2020).

5. Cyclo Olefin Copolymer (COC). Available online: https://us.mitsuichemicals.com/service/product/apel.htm (accessed on 13 August 2020).

6. Boggioni, L.; Sidari, D.; Losio, S.; Stehling, U.M.; Auriemma, F.; Di Girolamo, R.; De Rosa, C.; Tritto, I. Ethylene-co-norbornene copolymerization in the presence of a chain transfer agent. Eur. Polym. J. 2018, 107, 54-66. [CrossRef]

7. Li, X.; Hou, Z. Organometallic catalysts for copolymerization of cyclic olefins. Coord. Chem. Rev. 2008, 252, 1842-1869. [CrossRef]

8. Wang, B.; Long, Y.-Y.; Li, Y.-G.; Men, Y.-F.; Li, Y.-S. Cyclic olefin copolymers of propylene with asymmetric Si-containing $\alpha, \omega$-diolefins: The tailored thermal and mechanical properties. Polymer 2015, 61, 108-114. [CrossRef]

9. Kaminsky, W. Polymerization catalysis. Catal. Today 2000, 62, 23-34. [CrossRef]

10. Kaminsky, W.; Arndt, M. Metallocenes for Polymer Catalysis, Polymer Synthesis/Polymer Catalysis; Springer: Berlin/Heidelberg, Germany, 1997; pp. 143-187.

11. Boggioni, L.; Sidari, D.; Losio, S.; Stehling, U.M.; Auriemma, F.; Malafronte, A.; Di Girolamo, R.; De Rosa, C.; Tritto, I. Ethylene-co-norbornene Copolymerization Using a Dual Catalyst System in the Presence of a Chain Transfer Agent. Polymers 2019, 11, 554. [CrossRef]

12. Boggioni, L.; Tritto, I. State of the art of cyclic olefin polymers. MRS Bull. 2013, 38, 245-251. [CrossRef]

13. Frensdorff, H.K.; Pariser, R. Copolymerization as a Markov Chain. J. Chem. Phys. 1963, 39, 2303. [CrossRef]

14. Budagumpi, S.; Keri, R.S.; Biffis, A.; Patil, S.A. Olefin poly/oligomerizations by metal precatalysts bearing non-heterocyclic N-donor ligands. Appl. Catal. A Gen. 2017, 535, 32-60. [CrossRef]

15. Szeluga, U.; Moryc, P. Viscoelastic properties and morphology of dicyanate ester/epoxy co-polymers modified with polysiloxane and butadiene-acrylonitrile rubbers. J. Therm. Anal. Calorim. 2013, 114, 137-146. [CrossRef]

16. Kolosov, N.A.; Tuskaev, V.A.; Gagieva, S.C.; Fedyanin, I.V.; Khrustalev, V.N.; Polyakova, O.V.; Bulychev, B.M. Vanadium (V) and titanium (IV) compounds with 2-[hydroxy(diaryl)methyl]-8-hydroxyquinolines: Synthesis, structure and catalytic behaviors to olefin polymerization. Eur. Polym. J. 2017, 87, 266-276. [CrossRef]

17. Redshaw, C.; Walton, M.J.; Elsegood, M.R.J.; Prior, T.J.; Michiue, K. Vanadium(v) tetra-phenolate complexes: Synthesis, structural studies and ethylene homo-(co-)polymerization capability. RSC Adv. 2015, 5, 89783-89796. [CrossRef] 
18. Wang, J.-B.; Lu, L.-P.; Liu, J.-Y.; Li, Y.-S. [ONN]-type amine pyridine(s) phenolate-based oxovanadium(v) catalysts for ethylene homo- and copolymerization. Dalton Trans. 2014, 43, 12926-12934. [CrossRef] [PubMed]

19. Nomura, K.; Zhang, S. Design of Vanadium Complex Catalysts for Precise Olefin Polymerization. Chem. Rev. 2011, 111, 2342-2362. [CrossRef] [PubMed]

20. Hagen, H.; Boersma, J.; van Koten, G. Homogeneous vanadium-based catalysts for the Ziegler-Natta polymerization of $\alpha$-olefins. Chem. Soc. Rev. 2002, 31, 357-364. [CrossRef]

21. Ochędzan-Siodłak, W.; Bihun, A. Copolymerization of ethylene with norbornene or 1-octene using supported ionic liquid systems. Polym. Bull. 2017, 74, 2799-2817. [CrossRef]

22. Elagab, H.A.; Alt, H.G. Ti, Zr and V complexes with N-allyl functionalized heterocyclic ligands as catalysts for ethylene polymerization. Polyhedron 2016, 115, 17-29. [CrossRef]

23. Zanchin, G.; Gavezzoli, A.; Bertini, F.; Ricci, G.; Leone, G. Homo- and Copolymerization of Ethylene with Norbornene Catalyzed by Vanadium(III) Phosphine Complexes. Molecules 2019, 24, 2088. [CrossRef]

24. Zanchin, G.; Vendier, L.; Pierro, I.; Bertini, F.; Ricci, G.; Lorber, C.; Leone, G. Homo- and Co-Polymerization of Ethylene with Cyclic Olefins Catalyzed by Phosphine Adducts of (Imido)vanadium(IV) Complexes. Organometallics 2018, 37, 3181-3195. [CrossRef]

25. Zanchin, G.; Pierro, I.; Parisini, E.; Martí-Rujas, J.; Ricci, G.; Leone, G. Synthesis, structure and behavior of vanadium(III) diphosphine complexes in the homo- and co-polymerization of ethylene with norbornene: The ligand donor strength and bite angle make the difference. J. Organomet. Chem. 2018, 861, 142-150. [CrossRef]

26. Ochędzan-Siodłak, W.; Bihun-Kisiel, A.; Siodłak, D.; Poliwoda, A.; Dziuk, B. Titanium and vanadium catalysts with oxazoline ligands for ethylene-norbornene (co)polymerization. Eur. Polym. J. 2018, 106, 148-155. [CrossRef]

27. Wang, H.; Cheng, H.; Tanaka, R.; Shiono, T.; Cai, Z. Efficient control of ethylene-norbornene copolymerization behavior of a fluorenylamido-ligated titanium complex: Substituent effects of the amido ligand and copolymer properties. Polym. Chem. 2018, 9, 4492-4497. [CrossRef]

28. Wu, J.-Q.; Li, Y.-S. Well-defined vanadium complexes as the catalysts for olefin polymerization. Coord. Chem. Rev. 2011, 255, 2303-2314. [CrossRef]

29. Langeslay, R.R.; Kaphan, D.M.; Marshall, C.L.; Stair, P.C.; Sattelberger, A.P.; Delferro, M. Catalytic Applications of Vanadium: A Mechanistic Perspective. Chem. Rev. 2019, 119, 2128-2191. [CrossRef]

30. Diteepeng, N.; Tang, X.; Hou, X.; Li, Y.-S.; Phomphrai, K.; Nomura, K. Ethylene polymerisation and ethylene/norbornene copolymerisation by using aryloxo-modified vanadium(v) complexes containing 2,6-difluoro-, dichloro-phenylimido complexes. Dalton Trans. 2015, 44, 12273-12281. [CrossRef]

31. Liu, Y.; Xiang, H.-X.; Wang, K.-T.; Wu, G.; Li, Y.-B. Efficient Preparation of Cyclic Olefin Copolymers with Unreacted Double Bonds by Using Thermal Stable Non-Metallocene Vanadium Catalytic System. Macromol. Chem. Phys. 2019, 220, 1900008. [CrossRef]

32. Wang, W.; Nomura, K. Notable Effects of Aluminum Alkyls and Solvents for Highly Efficient Ethylene (Co)polymerizations Catalyzed by (Arylimido)- (aryloxo)vanadium Complexes. Adv. Synth. Catal. 2006, 348, 743-750. [CrossRef]

33. Wu, J.-Q.; Mu, J.-S.; Zhang, S.-W.; Li, Y.-S. Vanadium(V) complexes containing tetradentate amine trihydroxy ligands as catalysts for copolymerization of cyclic olefins. J. Polym. Sci. Part A Polym. Chem. 2010, 48, 1122-1132. [CrossRef]

34. Desimoni, G.; Faita, G.; Jørgensen, K.A. C2-Symmetric Chiral Bis(Oxazoline) Ligands in Asymmetric Catalysis. Chem. Rev. 2006, 106, 3561-3651. [CrossRef]

35. Phillips, A.M.F.; Suo, H.; Guedes da Silva, M.d.F.C.; Pombeiro, A.J.L.; Sun, W.-H. Recent developments in vanadium-catalyzed olefin coordination polymerization. Coord. Chem. Rev. 2020, 416, 213332. [CrossRef]

36. Ben Zid, T.; Fadhli, M.; Khedher, I.; Fraile, J.M. New bis(oxazoline)-vanadyl complexes, supported by electrostatic interaction in Laponite clay, as heterogeneous catalysts for asymmetric oxidation of methyl phenyl sulfide. Microporous Mesoporous Mater. 2017, 239, 167-172. [CrossRef]

37. Javadi, M.M.; Moghadam, M.; Mohammadpoor-Baltork, I.; Tangestaninejad, S.; Mirkhani, V. Epoxidation of alkenes and oxidation of sulfides catalyzed by a new binuclear vanadium bis-oxazoline complex. J. Iran. Chem. Soc. 2015, 12, 477-485. [CrossRef]

38. Pastor, I.M.; Adolfsson, H. Novel highly modular C2-symmetric oxazoline ligands-Application in titanium-catalyzed diethylzinc additions to aldehydes. Tetrahedron Lett. 2002, 43, 1743-1746. [CrossRef] 
39. Tanaka, S.; Tada, M.; Iwasawa, Y. Enantioselectivity promotion by achiral surface functionalization on $\mathrm{SiO}_{2}$-supported $\mathrm{Cu}$-bis(oxazoline) catalysts for asymmetric Diels-Alder reactions. J. Catal. 2007, 245, 173-183. [CrossRef]

40. Kandasamy, K.; Singh, H.B.; Butcher, R.J.; Jasinski, J.P. Synthesis, Structure and Catalytic Properties of VIV, MnIII, MoVI and UVI Complexes Containing Bidentate (N, O) Oxazine and Oxazoline Ligands. Inorg. Chem. 2004, 43, 5704-5713. [CrossRef] [PubMed]

41. Bagherzadeh, M.; Esmailpour, P.; Abbasi, A.; Akbari, A.; Amini, M. Synthesis, crystal structure and catalytic activity of an oxo-diperoxo tungsten(VI) complex containing an oxazine ligand for selective oxidation of sulfides. J. Coord. Chem. 2018, 71, 3405-3414. [CrossRef]

42. Selvam, T.; Machoke, A.; Schwieger, W. Supported ionic liquids on non-porous and porous inorganic materials-A topical review. Appl. Catal. A Gen. 2012, 445-446, 92-101. [CrossRef]

43. Van Doorslaer, C.; Wahlen, J.; Mertens, P.; Binnemans, K.; De Vos, D. Immobilization of molecular catalysts in supported ionic liquid phases. Dalton Trans. 2010, 39, 8377-8390. [CrossRef]

44. Ochędzan-Siodłak, W.; Dziubek, K. Metallocenes and post-metallocenes immobilized on ionic liquid-modified silica as catalysts for polymerization of ethylene. Appl. Catal. A Gen. 2014, 484, 134-141. [CrossRef]

45. Ochędzan-Siodłak, W.; Bihun, A. Direct synthesis of fibrous high molecular weight polyethylene using vanadium catalysts supported on an $\mathrm{SiO} 2$ ionic liquid system. Polym. Int. 2015, 64, 1600-1606. [CrossRef]

46. Ochędzan-Siodłak, W.; Bihun, A.; Olszowy, A.; Rajfur, M.; Jesionowski, T.; Siwińska-Stefańska, K. Ethylene polymerization using vanadium catalyst supported on silica modified by pyridinium ionic liquid. Polym. Int. 2016, 65, 1089-1097. [CrossRef]

47. Tritto, I.; Boggioni, L.; Ferro, D.R. Metallocene catalyzed ethene- and propene co-norbornene polymerization: Mechanisms from a detailed microstructural analysis. Coord. Chem. Rev. 2006, 250, 212-241. [CrossRef]

48. Białek, M.; Czaja, K.; Sacher-Majewska, B. Studies of structural composition distribution heterogeneity in ethylene/1-hexene copolymers using thermal fractionation technique (SSA): Effect of catalyst structure. Thermochim. Acta 2005, 429, 149-154. [CrossRef]

49. Hosoda, S. Structural distribution of linear low-density polyethylenes. Polym. J. 1988, 20, 383-397. [CrossRef]

50. Fineman, M.; Ross, S.D. Linear method for determining monomer reactivity ratios in copolymerization. J. Polym. Sci. 1950, 5, 259-262. [CrossRef]

51. Tritto, I.; Boggioni, L.; Jansen, J.C.; Thorshaug, K.S.; Maria, C.; Ferro, D.R. Ethylene-norbornene copolymers from metallocene-based catalysts: Microstructure at tetrad level and reactivity ratios. Macromolecules 2002, 35, 616-623. [CrossRef]

52. Hsieh, E.T.; Randall, J.C. Monomer sequence distributions in ethylene-1-hexene copolymers. Macromolecules 1982, 15, 1402-1406. [CrossRef]

53. Busico, V.; Cipullo, R.; Friederichs, N.; Linssen, H.; Segre, A.; Van Axel Castelli, V.; van der Velden, G. H NMR analysis of chain unsaturations in ethene/1-octene copolymers prepared with metallocene catalysts at high temperature. Macromolecules 2005, 38, 6988-6996. [CrossRef]

54. Kokko, E.; Pietikäinen, P.; Koivunen, J.; Seppälä, J.V. Long-chain-branched polyethene by the copolymerization of ethene and nonconjugated $\alpha, \omega$-dienes. J. Polym. Sci. Part A Polym. Chem. 2001, 39, 3805-3817. [CrossRef]

55. Ochędzan-Siodłak, W.; Dziubek, K.; Czaja, K. Effect of immobilization of titanocene catalyst in aralkyl imidazolium chloroaluminate media on performance of biphasic ethylene polymerization and polyethylene properties. Polym. Bull. 2013, 70,1-21. [CrossRef]

56. Müller, A.J.; Michell, R.M.; Pérez, R.A.; Lorenzo, A.T. Successive self-nucleation and annealing (SSA): Correct design of thermal protocol and applications. Eur. Polym. J. 2015, 65, 132-154. [CrossRef]

Publisher's Note: MDPI stays neutral with regard to jurisdictional claims in published maps and institutional affiliations. 